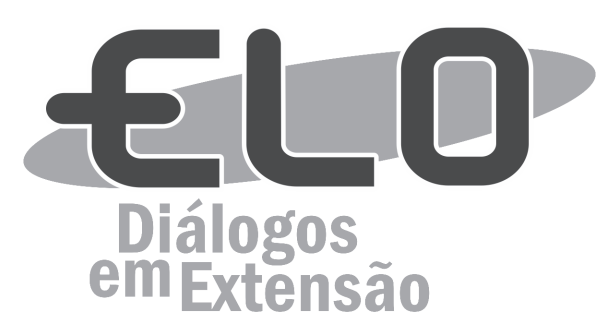

\title{
O processo de expressão da identidade local no artesanato da Associação Municipal de Artesãos de Paula Cândido (AMAPAC)
}

Lívia Rabelo ${ }^{1}$, Leilane Rigoni Bossatto ${ }^{2}$, Ademar Sodré3 , Bianca Aparecida Costa Lima

\begin{abstract}
Resumo: A Incubadora Tecnológica de Cooperativas Populares (ITCP-UFV) auxilia grupos populares pautados pelos princípios da economia solidária, como é o caso da Associação Municipal de Artesãos de Paula Cândido (AMAPAC). Nesse sentido, o objetivo desse artigo é apresentar parte do processo de incubação da AMAPAC pela ITCP-UFV, com foco na valorização e reconhecimento da identidade local e grupal, culminado em peças artesanais que expressam a cultura local e o modo de produção na Economia Solidária. A metodologia utilizada, a fim de compreender a dinâmica interna do grupo, foi a observação participante e as oficinas utilizadas para alcançar os objetivos diagnosticados. Como resultado percebeu-se o interesse em dar visibilidade à elementos tradicionais do município e ao modo de produção utilizado, além da preocupação com o meio ambiente e a inclusão social. Observou-se também que, apesar da união do grupo, a não organização das ideias impossibilitava a efetivação dos objetivos.
\end{abstract}

Palavras-chave: Artesanato. AMAPAC. Cultura. Identidade. Economia Solidária.

Área Temática: Cultura, Teorias e Metodologias em Extensão.

\section{The process of cultural identity's expression on the craftwork of the Local Craftsman's Association of Paula Cândido (AMAPAC)}

\begin{abstract}
The Technological Incubator of Popular Cooperatives (ITCP-UFV) helps popular groups guided by the principles of Solidarity Economy, such as the Municipal Association of Paula Cândido Craftsman (AMAPAC). In this sense, the objective of this paper is to present part of the AMAPAC incubation process by ITCP-UFV, focusing on appreciation and recognition of the local and group identity, culminating in pieces that express the local culture and the mode of production in the Solidarity Economy. The methodology used in order to understand the internal dynamics of the group was the participant observation and the use of workshops to achieve the objectives diagnosed by observation. As a result it was noticed the interest in giving visibility to the traditional elements of the municipality and the production method used, as well as concern for the environment and social inclusion. It is also noted that despite the group's unity, the absence of organized ideas precluded the realization of goals.
\end{abstract}

Keywords: Craftwork. AMAPAC. Culture. Iidentity. Sympathetic Economy.

Thematic area: Culture, Theories and Extension Methodologies.

\footnotetext{
${ }^{1}$ Graduada e Mestre em Ciências Econômicas e Graduanda em Ciências Sociais - Universidade Federal de Viçosa (UFV). Endereço: Rua Jorge Ramos, n 80 . Bairro Santo Antônio, Viçosa - MG. Telefone: (31) 99490 4511. E-mail: livia.rabelo@ufv.br

${ }^{2}$ Graduada e Mestre em Economia Doméstica - Universidade Federal de Viçosa (UFV). E-mail: leilaneitcp@gmail.com

${ }^{3}$ Graduando em Cooperativismo - Universidade Federal de Viçosa (UFV). E-mail: ademar.sodre@ufv.br

${ }^{4}$ Graduada em Jornalismo, Mestre e Doutora em Ciências Sociais. Professora adjunta da Universidade Federal de Viçosa (UFV). Orientadora do artigo. E-mail:

biancaitcpufv@gmail.com
} 


\section{El proceso de la expresión de la identidad local en la artesania de la Asociación Municipal de Artesanos de Paula Cândido (AMAPAC)}

Resumen: La Incubadora Tecnológica de Cooperativas Populares (PICT-UFV) ayuda a los grupos de base guiadas por los principios de la Economía Solidaria, como la Asociación Municipal de Paula Cândido Craftsman (AMAPAC). En este sentido, el objetivo de este trabajo es presentar parte del proceso de incubación de la AMAPAC por la ITCP-UFV, centrándose en el aprecio de la identidad local y el grupo, que culminó con piezas que expresan la cultura local y el modo de producción en la Economía Solidaria. La metodología utilizada para entender la dinámica interna del grupo fue la observación participante y el uso de talleres para alcanzar los objetivos diagnosticados. Como resultado se observó el interés en dar visibilidad a los elementos tradicionales de la municipalidad y el método de producción utilizado, así como la preocupación por el medio ambiente y la inclusión social. También se observa que a pesar de la unidad del grupo, la falta de organización de ideias ha imposibilitado el logro de metas.

Palabras clave: Artesanía. AMAPAC. Cultura. Identidad. Economía Solidaria.

Áreas Temática: Cultura. Teorías y Metodologías en Extensión.

\section{Introdução}

A Economia Popular Solidária (EPS), no Brasil, vem crescendo fortemente nos anos recentes, tendo uma massa significativa de artesãos que se destacam pela fabricação de produtos manuais, ou seja, sem uso de máquinas de grandes proporções, criando produtos sustentáveis e bem aceitos no mercado. O termo "economia solidária" foi cunhado na década de 1990, quando cidadãos, produtores e consumidores iniciaram inúmeras atividades econômicas organizadas segundo princípios de cooperação, autonomia e gestão democrática. Segundo Laville e Gaiger (2009), o conceito de economia solidária é amplamente utilizado em vários continentes, com acepções variadas que giram ao redor da ideia de solidariedade, em contraste com o individualismo utilitarista, que caracteriza o comportamento econômico predominante nas sociedades de mercado.

De acordo com Vieira (2008), um dos ramos que compõem a EPS, que se mostra de suma importância para o seu desenvolvimento, é constituído de entidades de apoio com a função de fomentar, capacitar, dar suporte para o desenvolvimento e fortalecimentos dos Empreendimentos Econômicos Solidários (EES). É nesse ramo que se encontram as Incubadoras, juntamente a outras entidades, como as Organizações Não Governamentais (ONG's), sindicatos, entidades vinculadas à Igreja, entre outras.

Dada a importância do auxílio das Incubadoras aos EES, foi criada em 2003 a Incubadora Tecnológica de Cooperativas Populares da Universidade Federal de Viçosa (ITCP-UFV). A ITCPUFV é um programa de extensão universitária que tem por objetivo apoiar iniciativas coletivas visando seu fortalecimento nos aspectos econômicos, organizacionais e sociais. Busca-se a geração de trabalho e renda, a promoção do consumo consciente, do comércio justo, da segurança alimentar, da produção agroecológica e solidária, o desenvolvimento local sustentável e o fomento à cultura. Para tanto, a Incubadora atua de forma multidisciplinar, contando com estudantes e professores de diversas áreas do conhecimento acadêmico, além de promover a integração e diálogo entre o conhecimento científico e os saberes populares. A metodologia de incubação utilizada para o desenvolvimento das atividades é dividida em três fases: Pré-incubação, Incubação e Desincubação.

As atividades de extensão são articuladas à pesquisa e ao desenvolvimento de tecnologias sociais adequadas aos empreendimentos econômicos populares. Sendo assim, é de suma importância que as metodologias sejam rigorosamente sistematizadas para posterior divulgação dos resultados alcançados e para que possam, dessa forma, contribuir para o desenvolvimento de políticas públicas no campo da Economia Popular Solidária.

A ITCP-UFV está estruturada em equipes que trabalham com diversos segmentos produtivos, tais como: Artesanato e Cultura; Agricultura Familiar; e Reciclagem. O programa também conta com o Núcleo de Comunicação e Eventos e o Núcleo Contábil e Jurídico. Visando a organização e mobilização junto à Economia Popular Solidária, a ITCP conta, também, com o Núcleo Fóruns e Redes, que trabalha apoiando Fóruns e Redes, em especial o Fórum Mineiro de Economia Popular Solidária e a Rede Sudeste de ITCP's. 
Relativamente às atividades do segmento Artesanato e Cultura, estas se vinculam ao artesanato que se revela como expressão cultural de uma determinada localidade e envolve um significativo número de pessoas organizadas, geralmente, em associações e que expõem seus produtos manuais em feiras ou lojas. Esse tipo de atividade engloba tanto o campo como a cidade, mas de forma preponderante tem nas mulheres as protagonistas desses processos que buscam gerar trabalho e renda.

Um dos grupos incubados pela ITCP-UFV, assessorado mais especificamente pelo Segmento de Artesanato e Cultura, é a Associação Municipal dos Artesãos de Paula Cândido (AMAPAC). Esta associação está localizada no município de Paula Cândido, na Zona da Mata mineira, sendo formada por treze artesãs e um artesão, que se reúnem, frequentemente, para produzir suas peças artesanais e debater sobre os rumos que devem seguir como um empreendimento de economia solidária. A AMAPAC é uma associação que se preocupa não somente com a geração de renda, mas também com a forma com que essa renda é gerada, com seus impactos no meio ambiente e com a socialização dos membros da associação. Veem o artesanato como uma forma de socialização e o seu potencial terapêutico, assim, propõem projetos sociais que possam fomentar a inclusão social através do artesanato.

Nesse sentido, o artigo tem como objetivo apresentar parte do processo de incubação da AMAPAC pela ITCP-UFV, com foco na valorização e no reconhecimento da identidade local e grupal, culminado em peças artesanais que expressam a cultura do município de Paula Cândido e dão visibilidade ao modo de produção na Economia Solidária. Para tanto, o texto está estruturado da seguinte forma: 1) Referencial teórico: referencias teóricas com relação ao artesanato e aos conceitos de cultura, identidade e algumas tradições culturais de Paula Cândido, bem como considerações acerca dos métodos utilizados pela ITCP-UFV no seu trabalho de incubação da AMAPAC; 2) Resultados: mostrou-se os resultados auferidos, dando ênfase ao processo de incubação que se fez por intermédio da ITCP-UFV, assim como algumas considerações importantes acerca do trabalho realizado e do desenvolvimento da associação como empreendimento econômico solidário.

\section{Referencial teórico}

Segundo Laville e Gaiger (2009), o conceito de economia solidária é amplamente utilizado em vários continentes, com acepções variadas que giram ao redor da ideia de solidariedade, em contraste com o individualismo utilitarista que caracteriza o comportamento econômico predominante nas sociedades de mercado.

Entre os vários setores que produzem de forma solidária, o artesanal se destaca em razão da sua forma característica de produção. Entretanto, o termo artesanato não é tão simples de ser definido, pois não há consenso na literatura acerca do significado a ele atribuído. $\mathrm{O}$ artesanato é abordado por alguns autores como Canclini (1983), Cascudo (2001), Martins (1973), Barroso (2009), Pinho (2002), Carreiro (1975), Serviço Brasileiro de Apoio às Micro e Pequenas Empresas (SEBRAE, 2004) e Rima (1977) de vários ângulos, seja pela forma como surgiu, pela utilidade aplicada, pela expressão artística, dentre outros.

Canclini (1983) expressa um grau de dificuldade em definir o artesanato em função do fato de que sua identidade e seus limites têm se tornado complexos nos últimos tempos, porque os produtos considerados artesanais modificaram-se ao se relacionarem com o mercado capitalista, a indústria cultural, o turismo e com as novas formas de lazer, comunicação e arte.

No entanto, há algumas tentativas de conceituar teoricamente o artesanato. No Brasil, citam-se aqui três exemplos de dedicação à formação desse termo. Em primeiro lugar, traz-se a contribuição do folclorista Luís da Câmara Cascudo, o qual afirma que o artesanato é "todo objeto utilitário com características folclóricas, não importando o material utilizado" (CASCUDO, 2001, p.24). Esta proposição se apresenta a partir das finalidades do produto.

Apresenta-se outra tentativa, no artigo "Produtos artesanais e mercados turísticos", no qual o artesanato é organizado em três designações: o "artesanato popular genuíno", em que se fala em qualidade, identidade e mercado consumidor; os "trabalhos manuais", com mão de obra menos qualificada, que visam fonte de renda; e o "industrianato", no qual um produto artesanal é alvo do processo de massificação (PINHO, 2002, p.171-172).

Outro aporte para essa discussão decorre do $\operatorname{SEBRAE~(2004,~p.21),~em~que~"o~artesanato~é~toda~}$ atividade produtiva que resulte em objetos e artefatos acabados, feitos manualmente ou com a utilização 
de meios tradicionais, com habilidade, destreza, qualidade e criatividade". Esta delimitação também se manifesta com base em usos, mas já se volta para a matéria-prima, ferramentas e outras peculiaridades da atividade.

O processo para o surgimento do artesanato é explicado por Rima (1977), em que durante a Idade Média, com o crescimento das cidades e da burguesia, bem como, com a excelência e abundância dos recursos naturais na Europa, conjugados com as técnicas de produção mais evoluídas dos homens, houve um aceleramento da ampliação dos mercados, possibilitando assim a especialização dos trabalhadores em determinados produtos, transformando-os em artesãos. Essa especialização e a divisão do trabalho resultaram na produção específica para o mercado, substituindo a produção para o autoconsumo, predominante até então.

Neste sentido, o artesanato saiu de um âmbito mais restrito, inicial, para ganhar o mercado, no qual teve que concorrer com os outros produtos mais industrializados, ganhando, assim, significação econômica. Segundo o SEBRAE, o Termo de Referência para o Artesanato (2004) é aquele em que o objeto artesanal se apropria de elementos que constituem a cultura material e imaterial se valendo de cores e formas das paisagens locais, da fauna e flora, do patrimônio histórico, da arquitetura típica, das lendas e festas populares, dos tipos humanos.

Referente a esse conceito, Paz (2006) argumenta que o artesanato está no centro de uma balança que pesa a beleza e a utilidade, a arte e a tecnologia. Assim, pode-se entender que o artesanato além de ser uma atividade produtiva, é também um meio de expressão cultural do homem comum.

O artesanato vem ganhando, cada vez mais, caráter de manifestação artística, ampliando seu alcance e alargando fronteiras, tendo se transformado em importante fonte de renda e de criação. Expressa, ainda, a experiência regional das comunidades, seu modo de fazer, sua vivência particular, enfim, seu modo de vida (SENAC, 2002).

O artesanato aqui é visto como uma forma de expressão, um modo de ser de uma comunidade, um modo de ver o mundo. Por isso a importância de situar produtos artesanais no tempo e espaço, ou seja, em qual localidade eles surgem, em que época, expressando quais aspectos da cultura dessa comunidade em que brotam, uma vez que esses elementos podem ser vistos como a representação de uma identidade local. Laraia (2001) afirma que o primeiro conceito etnográfico de cultura surgiu com Tylor (1871), que a definiu como um todo complexo, incluindo conhecimentos, crenças, arte, moral, leis, costumes ou qualquer outra capacidade ou hábitos adquiridos pelo homem como membro de uma sociedade.

Nesse sentido, Laraia (2001) enfatiza que a cultura é algo intrínseco ao ser humano, pois, na condição de ser social, não existe indivíduo sem cultura, não importando sua raça ou origem. A cultura é tida como diretriz e formadora da visão de mundo. Não existe cultura superior à outra, nem mais desenvolvida, nem mais lógica. Todas possuem seus princípios válidos para seus respectivos indivíduos.

Geertz (2008) chama de cultura as teias descritas por Max Weber ao afirmar que o homem é um animal amarrado a teia de significados que ele mesmo teceu. No âmbito cultural, os eventos, os fatos, os acontecimentos e os episódios, têm existência e sentido no momento, na época e no lugar de sua ocorrência.

De forma complementar, Cuche (2002) vê a cultura como necessária para se pensar a unidade da humanidade na diversidade. A cultura permite ao homem adaptar-se a seu meio e a este meio adaptar-se ao próprio homem e às necessidades dele. O homem é inteiramente interpretado pela cultura e os comportamentos são orientados pela cultura, assim, nada é puramente natural. Referindo-se à identidade, tem-se que a autonomia cultural é muito ligada à preservação da identidade coletiva.

Os termos cultura e identidade têm definições que remetem a uma mesma realidade. Nesse sentido, Cuche (2002) traz a concepção de identidade cultural, que remete ao grupo original de vinculação do indivíduo, ou seja, a sua origem, suas "raízes", seria então tudo que definiria o indivíduo de maneira real e verdadeira.

De acordo com Munanga (2012), na concepção da antropologia, acredita-se que a identidade consiste na soma de aglomerados nunca concluída de signos. Assim, a identidade está relacionada à ideia de alteridade, de forma que, a partir do outro e de suas características, o "eu" é definido, por comparação e diferença em relação as características do outro, com as quais se identifica. A identidade de um grupo funciona como uma ideologia, uma vez que permite que seus membros se definam em 
contraposição com outros grupos, reforçando sua solidariedade e visando conservar o grupo como entidade diferente.

Ampliando a discussão, insere-se a reflexão de Geertz (2008) quanto à importância, transmissão e ocorrência da cultura/tradição, argumentando que a cultura/tradição é pública exatamente por seu significado também ser público. Entretanto, analisando a transição das sociedades tradicionais para as modernas, é comum considerar a tradição como intrinsecamente conservadora. No entanto, pode-se dizer que esta possui papel de transformação, envolvendo processos ativos de reconstrução e nessa ação faz a ligação do presente com o passado (GIDDENS, 2001).

Assim sendo, Giddens (2001) observa que a tradição tem a missão ou funcionalidade de manter coesão e influenciar a ordem social. Segundo esse autor, essa funcionalidade não se opera de maneira mecânica e repetitiva ao longo do tempo, mas se constitui por uma intencionalidade de perpetuar os aspectos que geram identificação e segurança. Giddens (2001) afirma, ainda, que a tradição também está ligada à memória, especialmente a memória coletiva, envolve ritual e, ao contrário do costume, tem uma força de união que combina conteúdo moral e emocional. Nesse contexto, o ritual tem um sentido posto de forma intencional pelos membros da sociedade, que conhecem a intencionalidade e estão conscientes de seu sentido.

No que tange as manifestações tradicionais no município de Paula Cândido, um dos marcos da cultura local é expresso pelos rituais do Congado e Reinado, na Festa de Nossa Senhora do Rosário, que ocorre ininterruptamente desde 1853. Queiroz (2013) analisou a simbologia religiosa através da Festa, do Reinado e do Congado, para compreender a construção da identidade negra local. Nesse trabalho, entende que o catolicismo influenciou a composição da festividade, sendo assimilados elementos da religiosidade cristã por parte dos congadeiros. Apesar da influência católica, construiuse um processo dialético em que a tradição congadeira participa dos tempos e constrói a identidade e a memória dos grupos negros do Congado de Paula Cândido. Tal construção é realizada em contraste com os grupos brancos do Reinado, cujos mecanismos de legitimação, apesar de entrarem em atrito com o Congado, são também complementares.

Como esclarece Teixeira (2005), não é possível situar o catolicismo brasileiro num quadro de homogeneidade, porque ele é complexo e tem na pluralidade e diversidade seu traço constitutivo, existindo muitos estilos culturais de "ser católico". Diante disso, Bastide (1971) menciona dois catolicismos existentes no Brasil: o catolicismo branco e o negro ou do escravo. O catolicismo negro colocava-se ao lado do branco, entretanto, era visto numa esfera inferior da hierarquia, portanto julgado inferior. Embora de natureza similar, a estrutura da família patriarcal escravista inibia o igualitarismo cristão das duas partes: os negros não eram admitidos nas capelas, permanecendo do lado de fora, mas celebravam o fim da missa cantando um hino, às vezes em sua língua nativa, de forma que seu catolicismo foi uma subcultura de classe, assim como o foi, em certa medida, as religiões africanas. A partir disso, caracterizou-se uma construção de identidade não só negra, mas também católica.

Dessa forma, Tomaz (2000) afirma que a devoção a Nossa Senhora do Rosário aconteceu a partir das Irmandades existentes no período colonial. A Igreja procurou sobrepor sua cultura cristã em relação à africana, agregando o negro, considerado inferior, ao seu corpo de fiéis e neutralizando o impacto de seus rituais de adoração aos orixás sobre a tradição cristã. Ferretti (2007) acrescenta que além dessa imposição da religião dos colonizadores, aconteceu o sincretismo, elemento essencial de todas as formas de religião, muito presente na religiosidade popular e em diversos elementos da religião oficial. O sincretismo delineou-se não apenas como um fator de resistência à dominação cultural e religiosa, mas também como uma forma de fazer alianças, como o escravo aprendeu na senzala e nos quilombos.

Nesse contexto, Munanga (2012) argumenta que, se a construção do processo de identidade nasce a partir da tomada de consciência das diferenças entre "nós" e os "outros", em razão das diferenças dos contextos socioculturais aos quais o negro está inserido, não se pode afirmar a existência de uma comunidade identitária cultural entre grupos de negros que vivem em comunidades religiosas diferentes em comparação com a comunidade negra militante, ou com as comunidades remanescestes dos quilombos. Assim, afirma que "o conceito de identidade recobre uma realidade muito mais complexa do que se pensa, englobando fatores históricos, linguísticos, psicológicos, culturais, políticoreligiosos e raciais" (MUNANGA, 1988, p. 146).

Por entender a importância de se compreender os contextos em que o ator social está inserido, Queiroz (2013) buscou apreender o significado atribuído à tradicional Festa de Nossa Senhora do 
Rosário de Paula Cândido por aqueles que a praticam. Percebeu-se, então, que não se trata de simples recordações vagas do passado, mas sim de uma manifestação viva que é constantemente recriada. A Festa e o ritual são elementos que ressignificam a identidade negra, a partir da qual as festividades religiosas organizam um momento da vida social na busca de conectar o passado ao presente, demonstrando os vínculos particulares que a Festa mantém com o tempo, conferindo força simbólica para aqueles que a promovem. O Congado, com seus símbolos sagrados e culturais, apresenta de forma sintetizada um conjunto de valores, hábitos e costumes. Esse ritual proporciona, no grupo, o sentimento de pertencimento e a valorização da razão de ser congadeiro, articulando, portanto, o tempo irreversível e o reversível, a sincronia e a diacronia, no ritual da Festa em Paula Cândido.

A AMAPAC está localizada no município de Paula Cândido sendo formada por treze artesãs e um artesão. Os associados, em sua maioria, são graduados, sendo que muitos deles são aposentados como docentes ou ainda lecionam e veem no artesanato não somente uma forma de gerar renda como também forma terapêutica de aproveitar o tempo. No que tange à ITCP-UFV, que preza pela interdisciplinaridade, o Segmento de Artesanato e Cultura, responsável por acompanhar mais diretamente o processo descrito nesse artigo, é composto por seis estudantes, um bacharel e uma mestre nas áreas de Cooperativismo, Economia Doméstica, Economia e Ciências Sociais.

O processo de pré-incubação da AMAPAC iniciou-se em setembro de 2014, quando a presidente procurou a ITCP-UFV, no intuito de receber assessoramento e capacitações. A partir daí, foram realizadas reuniões a fim de esclarecer o que a associação desejava com a parceria e o que a ITCPUFV poderia oferecer com a incubação do empreendimento. Após os esclarecimentos, iniciou-se a incubação em outubro de 2014 e, posteriormente, foi construído o plano de ação que ainda orienta o processo.

A metodologia utilizada pela ITCP-UFV, a fim de se aproximar da realidade do grupo e conhecer sua história, a cultura local em que está inserido, sua dinâmica interna e as relações de poder estabelecidas, foi a abordagem qualitativa denominada observação participante. Essa metodologia consiste na imersão do pesquisador no grupo observado, vivenciando atividades cotidianas, buscando ganhar a confiança do grupo e compreendendo sua dinâmica interna para, assim, apreender o significado que o mesmo atribui às suas ações. Denzin (1989, p.157-158, apud Flick, 2009, p. 207) define a observação participante como "uma estratégia de campo que combina, simultaneamente, a análise de documentos, a entrevista de respondentes e informantes, a participação e a observação diretas e a introspecção".

Observar, conforme Marconi e Lakatos (2011), consiste em muito mais que ver e ouvir, sendo também uma forma de examinar os fenômenos estudados. A observação auxilia o pesquisador a obter provas sobre objetivos, que muitas vezes nem mesmo os indivíduos analisados têm consciência da existência, mas que, ainda assim, orientam seu comportamento.

Marconi e Lakatos (2011) afirmam, também, que, ao se incorporar no grupo, o pesquisador se confunde com ele, ficando tão próximo quanto um membro do grupo, sendo que o objetivo inicial dessa proximidade seria conquistar a confiança do grupo e apreender o significado atribuído internamente às ações. Não obstante, Whyte (2005) enfatiza a importância do pesquisador mostrarse diferente do grupo analisado, uma vez que as pessoas interessam-se pelo pesquisador exatamente por ele ser diferente do grupo. Portanto, esse pesquisador não deve tentar transformar-se em um nativo. Deve, no entanto, inserir-se como se fizesse parte do grupo, realizando conjuntamente as atividades em um exercício de ganho mútuo. Dito de outro modo, o pesquisador ajuda o grupo a realizar suas atividades cotidianas e o grupo ajuda o pesquisador ao fornecer não somente as informações, mas também ao permitir que o pesquisador vivencie as atividades cotidianas necessárias para a análise do grupo.

Segundo Laville e Dionne (1999), a técnica da observação participante está intimamente ligada à abordagem antropológica, pela qual os grupos são estudados de dentro, buscando compreender o universo simbólico grupal como ele é, evitando julgá-lo ou compará-lo a outro. Sendo também interessante já que, por meio da observação das atividades cotidianas, é possível verificar se as demandas apontadas pelo grupo analisado condizem com a realidade observada. De acordo com Laville e Dionne (1999), a observação deve respeitar certos critérios para ser qualificada como científica. Entretanto, essa rigidez não impede que haja um vasto leque de técnicas de observação partindo da mais estruturada até a menos estruturada. O caso clássico desta última é a observação participante, mas aqui se faz necessário esclarecer que, quando se classifica a observação como pouco ou não 
estruturada, isso não significa que a mesma esteja sem guia. Nesse caso, a observação é realizada baseando-se em uma hipótese, ainda que esta seja menos explícita que na observação estruturada, uma vez que o pesquisador pretende evitar os a priori. Nesse sentido, Gil (2008) aponta alguns elementos importantes para se ter em mente durante a observação, como pessoas, local, liderança, cooperação, etc.

Nessa metodologia, apesar da possibilidade de a observação ser realizada por apenas um pesquisador, Marconi e Lakatos (2011) salientam os benefícios da observação em equipe. Com mais de um observador, existe a possibilidade de cada um deles observar os mesmos elementos e, posteriormente, discutir sobre o que foi observado de modo a se alcançar um conhecimento intersubjetivo. Nesse sentido, cada membro do Segmento de Artesanato e Cultura da ITCP-UFV que acompanhou o processo inicial registrou suas descrições em seu caderno de campo, entre os meses de outubro e novembro de 2014 e, posteriormente, iniciou-se a sistematização e organização das informações coletadas. Além do caderno de campo, os encontros entre a Incubadora e a associação foram registrados tanto por fotos e vídeos, como também por uma relatoria oficial e listas de presença. A partir da análise dos dados foi possível, então, compreender melhor a organização do grupo para a construção coletiva de propostas em relação ao processo de apoio dado pela ITCP-UFV.

Faz-se importante salientar que essa observação ocorria não somente pela visita à associação em seu cotidiano de produção e realizações de reuniões, mas também durante eventos culturais da cidade em que os membros da associação estavam presentes, como a Festa de Nossa Senhora do Rosário, festas juninas nas quais seus produtos são vendidos, entre outros.

Após a observação, coleta, sistematização e análise dos dados, iniciou-se um conjunto de atividades entre as quais se encontram o resgate histórico, a oficina criativa e as oficinas de técnicas artesanais, entre os meses de novembro de 2014 e maio de 2015.

Ao se aproximar da AMAPAC, observou-se uma falta de reconhecimento da identidade cultural no artesanato local, ou seja, faltava algum elemento no produto que remetesse à cidade. Para que a oficina criativa fosse bem sucedida, iniciou-se um movimento de estímulo ao resgate cultural não somente da cidade de Paula Cândido na atualidade, mas também incluindo com ênfase os artesanatos locais, que foram produzidos ao longo da história da cidade. Esse resgate, apesar de direcionado pela ITCP-UFV, foi realizado pelos próprios artesãos. Essa é uma das preocupações da Incubadora, que preza para que os processos sejam realizados pelos próprios associados, restringindo à Incubadora apenas o fomento das discussões e auxílio para que o grupo se auto organize e possa continuar a se desenvolver após a desincubação. Para isso é necessário conhecer a dinâmica interna do grupo; com esse intuito, foram aplicadas também dinâmicas que proporcionaram conhecer a organização do grupo e sua união, além de destacar os líderes do grupo.

Segundo Cupertino (2001), a oficina criativa é estritamente voltada para a sensibilização e autoconhecimento dos envolvidos no processo, sendo concebida inicialmente para o desenvolvimento da criatividade. Migliori (1998) afirma que a oficina criativa tem sido aceita como uma nova forma de experiência educacional, representando uma metodologia que possibilita o surgimento de novas visões de mundo e de si mesmo, por intermédio de um intenso trabalho interno.

A oficina criativa realizada com a AMAPAC deu-se em três encontros. No primeiro deles, foi apresentado um vídeo motivacional sobre artesãos que davam visibilidade à cultura regional por meio de suas peças artesanais. Posteriormente, foram sistematizadas as peças que poderiam ser produzidas pelos artesãos da associação, problematizando os elementos essenciais da cultura local já pesquisados e recordados na etapa que denominamos resgate histórico, bem como as cores que estariam presentes nas peças. Apoiados em uma dinâmica criativa, cada artesão elencou em uma folha as peças que já produziam e o que poderia ser modificado nessas peças para que expressasse a identidade de Paula Cândido. No encontro seguinte, cada artesão levou os materiais necessários para confeccionar, de forma coletiva, suas peças modificadas pela impressão das características locais. E no terceiro momento, após o período de confecção, as peças foram avaliadas pelo coletivo surgindo mais ideias para melhorar a confecção.

Após a Oficina Criativa, os artesãos iniciaram um processo de imprimir um significado local nas peças produzidas e, após algumas reuniões entre a associação e a Incubadora, demonstraram interesse não só por imprimir a identidade local nos produtos, mas também para que a produção contribuísse para a reutilização de materiais que seriam inutilizados e aumentariam o lixo da cidade. Nesse sentido, foram oferecidas oficinas de técnicas pela ITCP-UFV, para que se pudesse conciliar técnicas artesanais à criatividade aflorada durante a metodologia aplicada, a qual se embasou na apropriação da 
identidade local. O foco das oficinas consistiu na reutilização de garrafas e potes de vidro para decoração e uso doméstico.

\section{Resultados}

Após a análise de dados coletados a partir da observação participante, identificou-se a forma organizacional da associação baseada na cooperação, como ficou evidente durante a dinâmica "Caneta na Garrafa", que tem o objetivo de trabalhar a integração, interdependência e sinergia nas atividades em equipe. Nessa primeira dinâmica (Figura 1), cortou-se vários pedaços de barbante de tamanhos desiguais e fixou-se uma das pontas de cada pedaço à uma caneta. As outras extremidades de cada pedaço do barbante foram seguradas por cada um dos associados, que se organizaram em roda. Em seguida, as pessoas deveriam trabalhar de forma conjunta para tentar colocar a caneta dentro de um copo, que se encontrava no meio da roda. Essa dinâmica foi fundamental para destacar a união em que o grupo se encontra, mostrando como trabalham coletivamente, auxiliando uns aos outros na resolução do problema proposto pela dinâmica, mantendo a comunicação contínua e a motivação entre eles. Além disso, a realização dessa atividade possibilitou identificar os membros que lideram o grupo, estimulando-os a serem mais ativos no sentido de motivar sempre os outros membros da associação. O objetivo da dinâmica foi alcançado rapidamente, graças ao trabalho que foi realizado em grupo, mostrando a união como uma característica fundamental dessa associação.

Atribui-se essa afinidade entre os integrantes ao fato de serem pessoas com interesses em comum, ou seja, além de compartilharem um mesmo modo de vida, são pessoas que se associaram para produzir de maneira alternativa, preocupados com a sustentabilidade, a inclusão social e o afloramento da tradição cultural local.

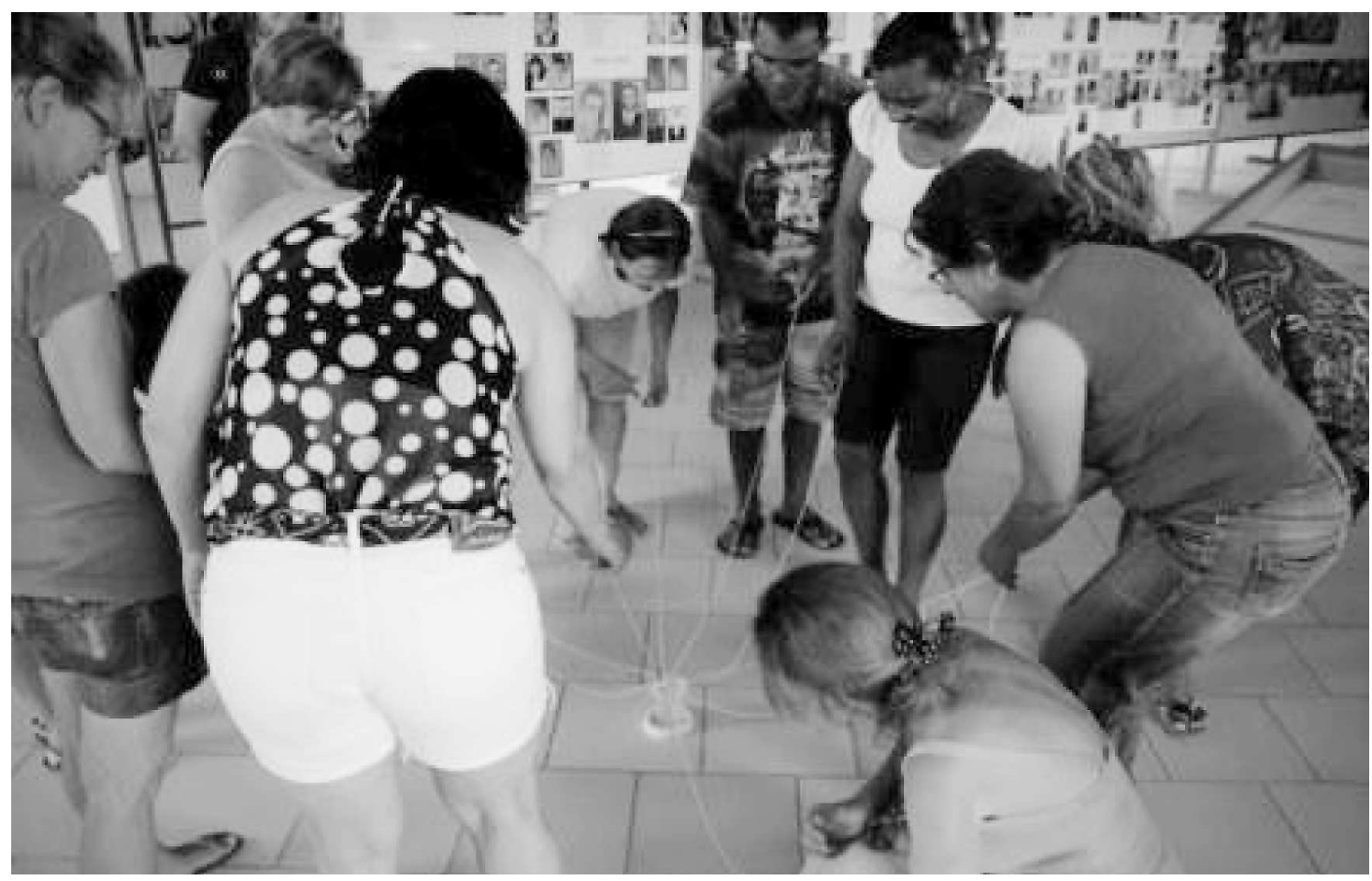

Figura 2 - Dinâmica de grupo "Caneta na garrafa”.

Fonte: ITCP-UFV.

A AMAPAC é uma associação motivada, ativa e interessada nos movimentos da Economia Solidária, tendo presença efetiva dos membros da associação nas reuniões do Fórum Regional de Economia Solidária. Logo após o início da incubação, a associação se mostrou muito interessada em participar da primeira Feira Regional de Economia Solidária da Zona da Mata Mineira (FRES-ZMM), que foi realizada em Viçosa entre os dias 13 e 16 de novembro de 2014, um espaço que prezou pela maior integração dos grupos, além de ser uma maneira de dar visibilidade às possíveis formas de se produzir alternativamente, pautados pelos princípios econômicos solidários. Nesse momento, pôde- 
se verificar a capacidade da AMAPAC em se organizar, já que rapidamente foi estabelecido quais os membros da associação iriam representar a associação na exposição da feira, em quais dias cada um ficaria responsável pela exposição, quais artesãs ficariam responsáveis por oferecer uma oficina de artesanato e qual produto seria ensinado nessa oficina. A Oficina de Bolas Natalinas (Figura 2) oferecida pela AMAPAC na FRES-ZMM foi temática, dada a proximidade da data na qual se comemora o Natal, tendo como facilitadoras duas artesãs da associação, que ensinaram como produzir um enfeite de Natal chamado "bolas natalinas".

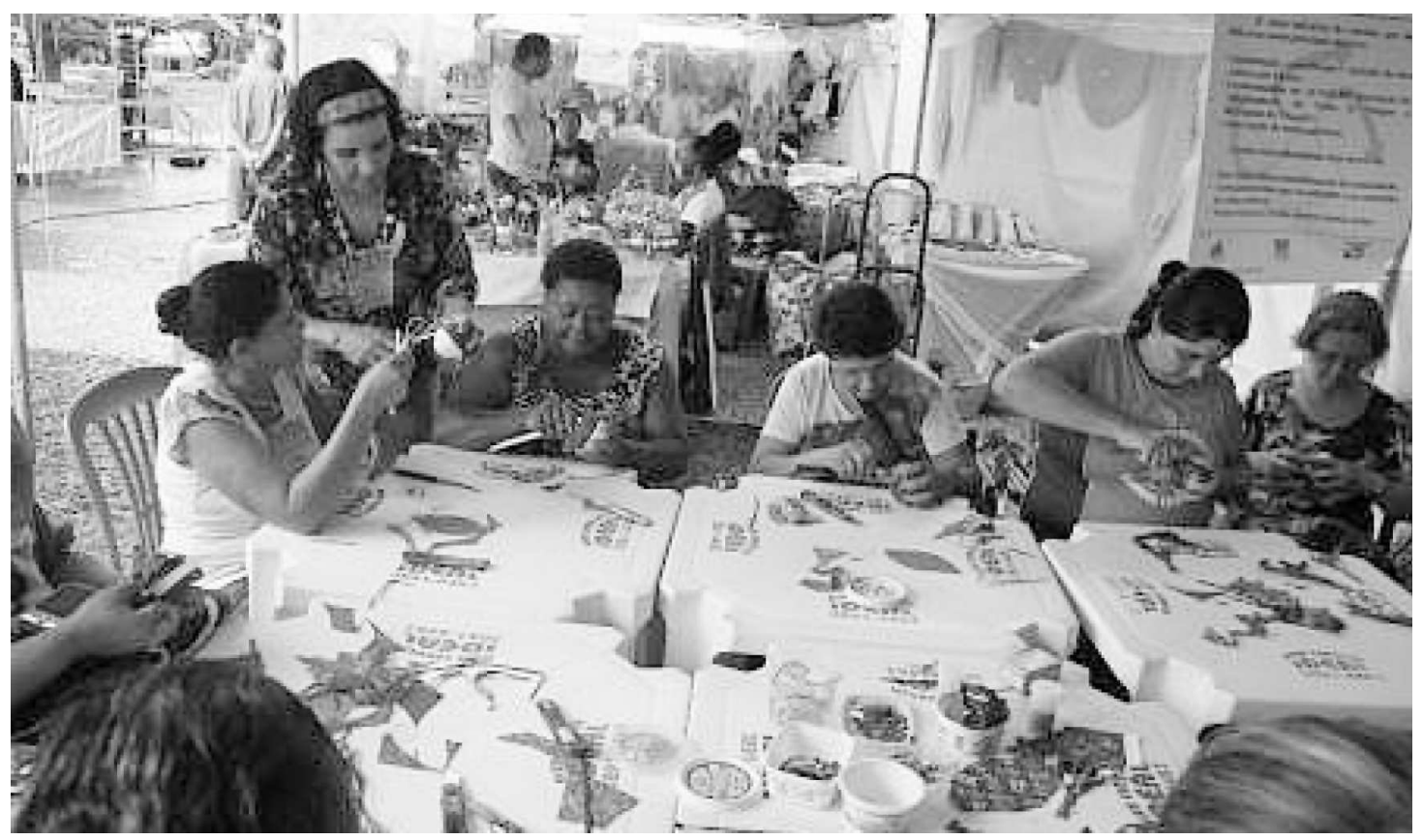

Figura 2 - Oficina de Bolas Natalinas oferecida pela AMAPAC na FRES-ZMM - 2014. Fonte: ITCP-UFV.

Entende-se que os associados da AMAPAC adquiriram hábitos ligados à cooperação e à solidariedade ao logo de suas histórias, o que fez com que se agrupassem a fim de lograr objetivos em comum. Por viverem em uma cidade de pequeno porte e serem pessoas ligadas à educação, preocupamse com o futuro e o bem estar dos moradores do município. Essa identidade grupal funciona como uma ideologia e permite aos associados que se definam em contraposição a outros grupos. Dentro da identidade grupal identificada, um dos interesses desses artesãos é a preservação da identidade de Paula Cândido, por isso a necessidade de um resgate e aprofundamento de elementos tão cotidianos que, por vezes, são banalizados.

No que tange ao processo da Oficina Criativa, entre os resultados obtidos, pôde-se perceber que as atividades realizadas, ao debater o sentido e o significado do artesanato, permitiram aflorar o sentimento dos artesãos referentes às características locais e culturais que pudessem ser expressas em seus produtos, como já discutido durante o resgate histórico e cultural. Tal resgate foi de extrema importância para o processo da apropriação da identidade local pelos artesãos, pois o grupo fez o levantamento de diversas características da cidade, não somente relacionadas ao artesanato, mas também a elementos culturais, sociais e econômicos, que poderiam estar presentes em suas peças como uma forma de remeter ao município de Paula Cândido.

Os associados levaram peças antigas que herdaram dos antepassados e relembraram ícones do artesanato local, como as peças em crochê e macramé, colchas de retalho, entre outras, etc. O levantamento gerou reflexões e questionamentos, o que, por sua vez, motivou uma nova forma de pensar o artesanato como uma forma de manter viva uma tradição local e de repensar o modo de produção, dito de outro modo, ocasionou o redesenhamento dos artesanatos atuais baseado em uma visão histórica do processo e cultural do município.

Percebeu-se, em conversas informais durante acompanhamento do processo produtivo, o forte simbolismo, tanto material quanto imaterial, que as peças produzidas carregam em si. De forma 
semelhante a textos imagéticos, como a fotografa, as peças artesanais contam a história local reproduzida por meio das mãos do artesão que uniu seus saberes cotidianos a uma pesquisa histórica, a fim dar visibilidade aos modos de vida da sua comunidade. O sentimento de pertencimento a esse conjunto de hábitos, costume e valores sintetizados pela Festa de Nossa Senhora do Rosário é tão representativo, que necessita ser eternizado por fotografias, mas também por peças decorativas que remetam a essa comunidade.

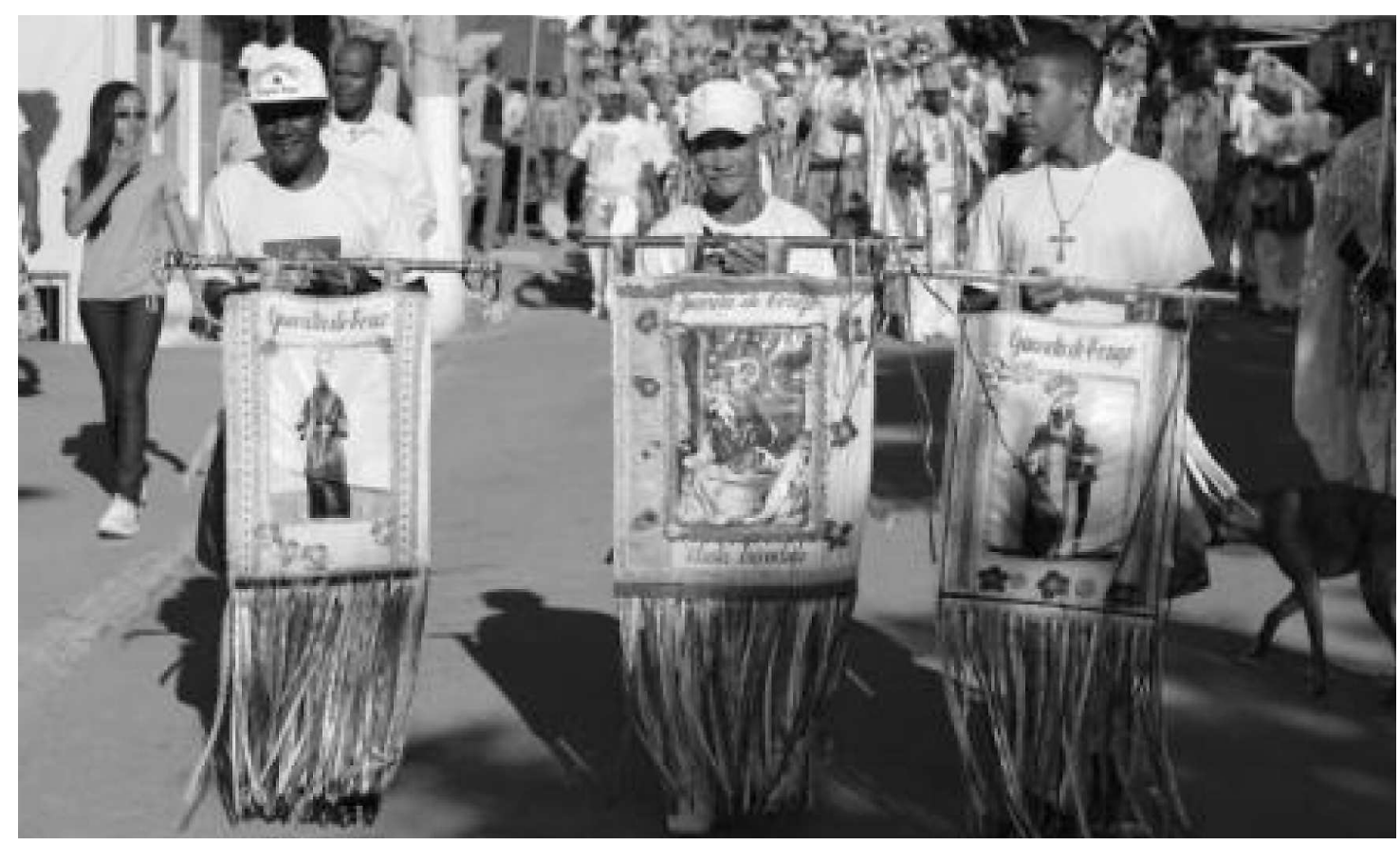

Figura 3 - Ritual do Congado, na Festa de Nossa Senhora do Rosário. Fonte: ITCP-UFV.

Nas reuniões posteriores, em especial no segundo encontro referente à Oficina Criativa (Figura 4), os artesãos expuseram suas ideias mais amadurecidas, bem como o que se propunha a produzir naquele momento e o que havia sido modificado nas peças.

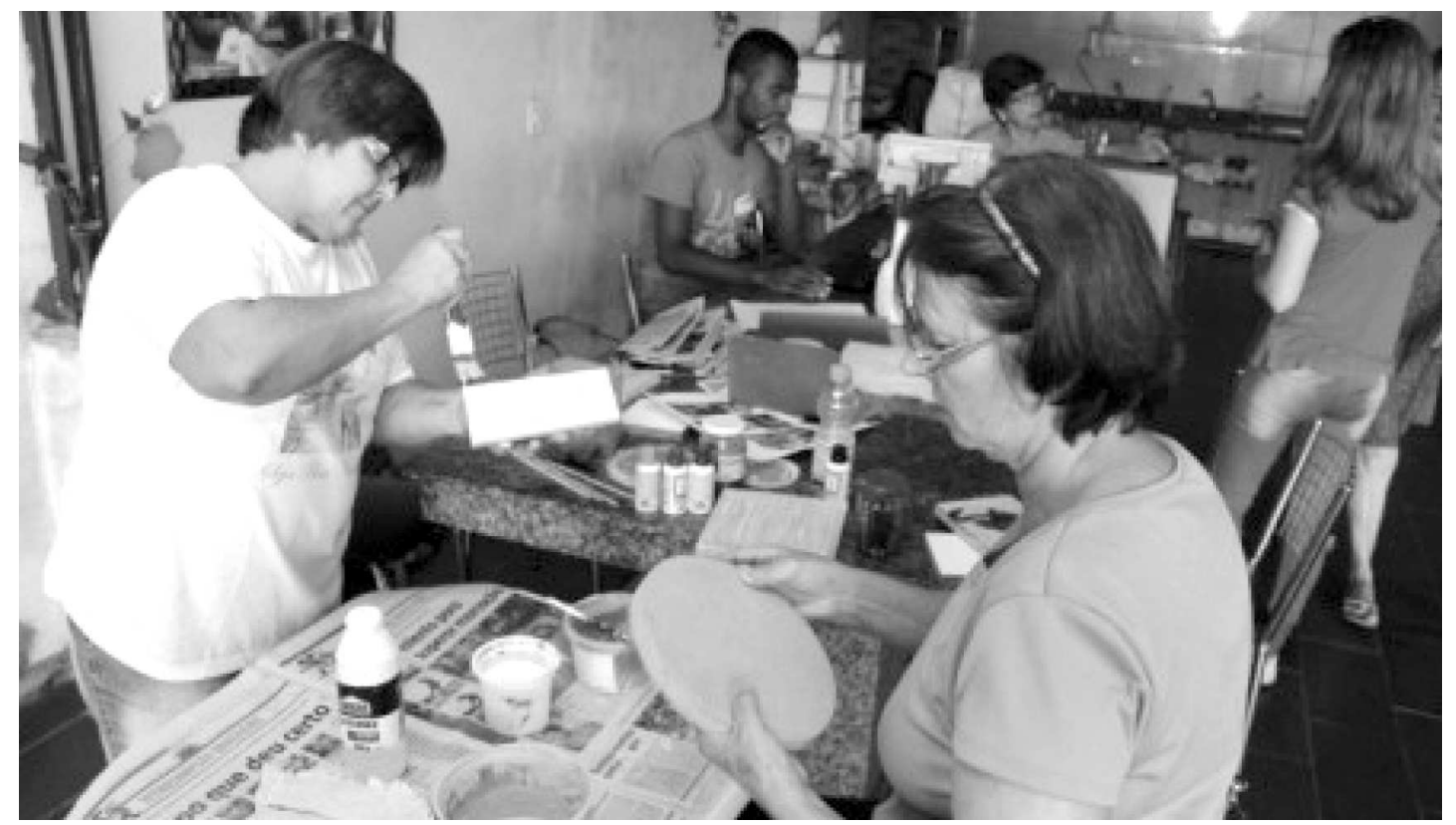

Figura 4 - Segundo encontro da Oficina Criativa, etapa de produção coletiva para inserir os elementos culturais nas peças já produzidas. Fonte: ITCP-UFV. 
É importante salientar que os elementos introduzidos nas peças artesanais, para que fossem identificadas como um artesanato de Paula Cândido, foram trazidos pelos próprios artesãos, baseados em suas vivências, suas histórias, que lhes foram contadas por seus ancestrais, além de festas e rituais dos quais participavam.

Durante a intervenção da ITCP-UFV junto à AMAPAC, verificou-se que a associação segue princípios de sustentabilidade, ao buscar alternativas de produção usando materiais reutilizáveis. Um dos desejos dos artesãos, era a possibilidade de utilizar, como matéria prima, objetos que virariam lixo, reduzindo a poluição na cidade e mostrando a importância de se trabalhar de forma sustentável. Após algumas reuniões, decidiu-se por reutilizar garrafas e potes de vidro aplicando técnicas artesanais para que se tornassem peças decorativas ou de uso doméstico. Os artesãos participaram, então, de oficinas de técnicas artesanais, como Oficina de Découpage, de Vitrificação e de Craquelê. As peças produzidas ao final da Oficina de Découpage são mostradas abaixo, na Figura 5.

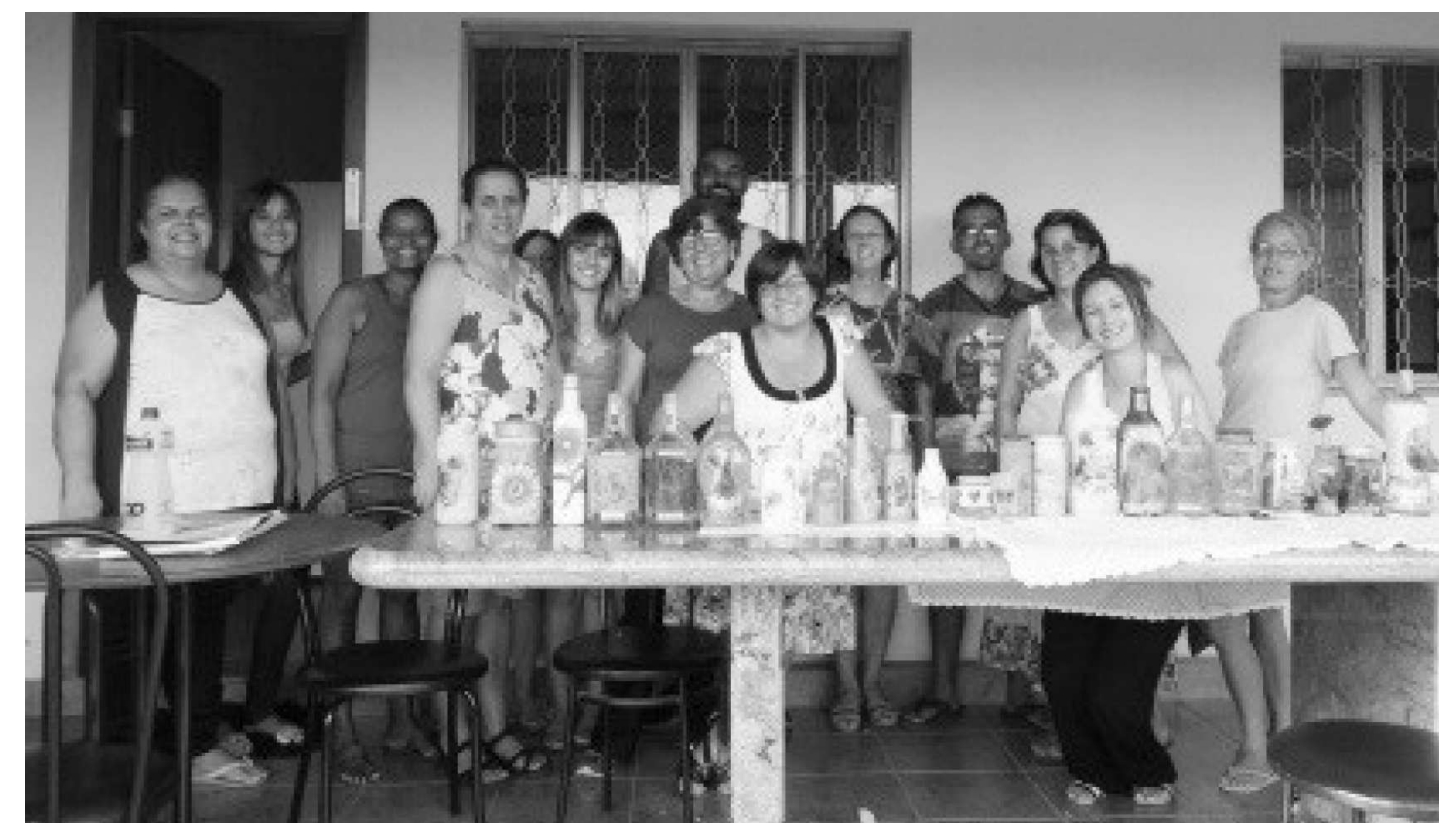

Figura 5 - Artesãos da AMAPAC e suas peças produzidas após a Oficina de Découpage. Fonte: ITCP-UFV.

Uma característica peculiar dessa associação é sua preocupação a com a inclusão social dos moradores da cidade de Paula Cândido. Por verem no artesanato uma forma de geração de renda, mas também uma forma de socialização, uma vez que pode ser visto como uma possibilidade de tratamento terapêutico, a AMAPAC decidiu por ampliar suas atividades, beneficiando a comunidade com um projeto social. Surgiu, então, a ideia de a associação realizar um projeto juntamente à Secretaria de Saúde do município, oferecendo oficinas de artesanato como uma forma de terapia para as pessoas atendidas e, ainda, contribuindo para a valorização da tradição e cultura local. A construção de tal projeto já se encontra em andamento, sendo discutido pela AMAPAC e pela Secretaria de Saúde de Paula Cândido, com o apoio da ITCP-UFV.

Considerando-se a identidade como a soma de um aglomerado de signos nunca concluída, acreditase que, simultaneamente ao fato de construírem uma conexão do passado com o presente, resgatando tradições locais, esses artesãos estão também envolvidos em um processo ativo de reconstrução da tradição e manutenção da ordem social. Ao mostrarem novas possibilidades de produção artesanal, tanto do ponto de vista do processo produtivo, quanto da matéria prima utilizada, assim como dos benefícios a serem proporcionados em termos terapêuticos, esses indivíduos podem trazer à tona uma nova realidade que, mesclada com uma realidade passada, tem a possibilidade de vir a ser a tradição local no futuro. Assim, mais do que a expressão de tradições locais em seus produtos, a AMAPAC sugere uma nova forma de se perceber o artesanato como um símbolo dos rituais, iniciados em um tempo remoto e que perdura ainda hoje, e também como um novo modo de se pensar o processo produtivo e a inclusão social. 
No decorrer do processo de intervenção foram alcançados grandes ganhos ao se tratar de autoconfiança, pois, a partir da Oficina Criativa, o grupo pôde perceber sua capacidade de criar o artesanato de maneira que ele remetesse à cultura da cidade. Apesar de estarem organizados a partir de objetivos em comum e trabalharem pautados pela cooperação, percebeu-se algumas dificuldades com relação à efetivação desses objetivos, pois as ideias não eram organizadas de forma a alcançar os resultados desejados.

Acredita-se que o projeto de extensão contribuiu para agilizar e facilitar um processo que pressupõe tempo, dialogicidade e uma intervenção educativa organizacional temporária, já que a ITCP-UFV atua como facilitadora para alcançar os objetivos almejados pela associação.

\section{Conclusões}

O trabalho elaborado na AMAPAC, além de trazer aprendizagem para os estudantes da ITCPUFV, por lhes permitir vivenciar experiências de práticas coletivas, conhecimento de tradições e manifestações culturais no município de Paula Cândido, trouxe também capacitação e inovação no conceito de identidade visual e cultural no artesanato da AMAPAC. Os benefícios trazidos pela produção coletiva do artesanato, que remete à cultura local, envolvem tanto a inclusão social, quanto estimula a prática do associativismo e cooperativismo pelos associados, além de valorizar elementos da tradição e cultura de Paula Cândido, que por serem tão presentes no cotidiano acabam sendo, muitas vezes, banalizados pelos moradores do município.

Através do artesanato, pode-se iniciar um processo de valorização e reconhecimento da identidade local, revivendo manifestações tradicionais e culturais, como a Festa de Nossa Senhora no Rosário e as peças artesanais que foram produzidas no passado e esquecidas após o falecimento dos artesãos especialistas. O artesanato produzido pela AMAPAC é, então, algo de grande importância e valor identitário do local, trazendo consigo uma forma de ocupação profissional para os artesãos, sendo uma possibilidade de geração de renda baseada nos princípios da economia solidária, que representa a gestão econômica e a autogestão organizacional.

Além disso, é importante ressaltar a pró-atividade da associação e as preocupações com questões sociais, ambientais e políticas. Tanto a ideia de reutilizar objetos que seriam inutilizados e aumentariam o lixo da cidade, quanto a ideia de se valer do conhecimento de técnicas artesanais para beneficiar os moradores da comunidade, partiram dos associados. A ITCP-UFV reservou-se à função de fomentar e problematizar as ideias, mostrar outras rotas possíveis de se chegar a um resultado para que eles escolhessem a mais adequada, e de apoiar questões técnicas e burocráticas.

Sendo assim, dada a inserção da AMAPAC em questões políticas discutidas durante as reuniões do Fórum Regional de Economia Solidária, sua inclinação para questões de preservação do meio ambiente, da inclusão social dos moradores do município e da eternização das festividades locais em seus produtos, entende-se que a associação é um empreendimento que serve de modelo para outros empreendimentos, iniciantes do processo, também pautados pelos princípios da economia solidária.

Fonte de financiamento: Os trabalhos realizados pela Incubadora Tecnológica de Cooperativas Populares da Universidade Federal de Viçosa (ITCP-UFV), recebem apoio financeiros do Conselho Nacional de Desenvolvimento Científico e Tecnológico (CNPQ), do Ministério do Trabalho e Emprego (MTE), do Programa de Extensão Universitária (PROEXT) e do Programa Nacional de Incubadoras de Cooperativas Populares (PRONINC), além do suporte pela Pró-Reitoria de Extensão e Cultura da Universidade Federal de Viçosa (PEC).

Agradecimentos: Gostaríamos de agradecer aos artesãos da AMAPAC, pelo carinho, dedicação e confiança, e por terem possibilitado essa importante troca de saberes que fez de nós seres humanos ainda mais sensíveis.

\section{Referências}

BARROSO, E. N. Design e artesanato. 2009. Disponível em:<http://www.eduardobarroso.com.br/ Artesanato_\%20mod1.pdf>. Acesso em: 5 out. 2012.

BASTIDE, R. As religiões africanas no Brasil: contribuição a uma sociologia das interpenetrações de civilizações. Trad. Maria Eloisa Capellato e Olívia Krähenbühl. São Paulo: Pioneira, 1971. 
CANCLINI, N.G. As culturas populares no capitalismo. São Paulo: Brasiliense, 1983.

CARREIRO, C. H. P. História do pensamento econômico. Rio de Janeiro: Rio, 1975.

CASCUDO, L. da C. Dicionário de folclore brasileiro. São Paulo: Global, 2001.

CUCHE, D. A noção de cultura nas ciências sociais. Bauru: EDUSC, 2002.

CUPERTINO, C. M. B. Criação e formação: fenomenologia de uma oficina. São Paulo: Arte \& Ciência, 2001.

FERRETTI, Sérgio. Sincretismo e Religião na Festa do Divino. In: Revista ANTHROPOLÓGICAS, ano 11, vol.18. p. 105 - 122, 2007.LARAIA, R. B. Cultura: um conceito antropológico. Rio de Janeiro: Jorge Zahar Ed., 2001.

LAVILLE, J. L; GAIGER, L. I. Economia Solidária. In: CATANNI, A. D.; LAVILLE, J.L.; GAIGER, L. I.; HESPANHA, P. Dicionário Internacional da outra economia. São Paulo: Almedina Brasil LTDA, 2009.

GEERTZ, C. A interpretação das culturas. Rio de Janeiro: LTC, 2008.

GIDDENS, A. Em defesa da sociologia: ensaios, interpretações e tréplicas. São Paulo, 2001.

MARTINS, S. Contribuição ao estudo científico do artesanato. Belo Horizonte: Imprensa do Estado de Minas Gerais. 1973. Disponível em: <www.eba.ufmg.br>. Acesso em: 8 jan. 2015.

MIGLIORI, R. Introdução. In: ALLESSANDRINI, C.D.; BRANDÃO, C.R.; LIMA, E.P. Criatividade e novas metodologias. Série Temas Trans-versais, Volume 4. São Paulo, Fundação Peirópolis, 1998.

MUNANGA, K. Construção da identidade negra: diversidade de contextos e problemas ideológicos. In: CONSORTE, Josildeth Gomes; COSTA, Márcia regina da (Orgs.). Religião, politica, identidade. São Paulo: Educ-séries cadernos PUC, 1988, p. 143-146.

MUNANGA, K. Negritude: usos e sentidos. Belo Horizonte: Autentica Editora, 2012.

PAZ, O. O uso e a contemplação. Revista Raiz: Cultura do Brasil, n 3. São Paulo: 2006. Disponível em: $<$ http:// revistaraiz.uol.com.br/portal/index. php?option $=$ com_content\&task=view\&id=102 \&Itemid=116>. Acesso em: 5 jan. 2015.

PINHO, M. S. M. de. Produtos artesanais e mercado turístico. In: MURTHA, S. M.; ALBANO, C. (Org). Interpretar o patrimônio: um exercício do olhar. Belo Horizonte: UFMG; Território Brasilis, 2002.

QUEIROZ, G. R. C. A Festa de Nossa Senhora do Rosário de Paula Cândido (MG): Identidade, memória e ritual no Congado e no Reinado. 2013.108 f. Dissertação (Mestrado em Ciência da Religião), Universidade Federal de Juiz de Fora, Juiz de Fora, 2013.

RIMA, I. H. História do pensamento econômico. São Paulo: Atlas, 1977.SEBRAE. Termo de referência do programa SEBRAE de artesanato. Brasília: SEBRAE, 2004.

SENAC, Serviço Nacional de Aprendizagem Comercial. Tintas e texturas, Rio de Janeiro. Ed. Senac Nacional, 2002. Disponível em:< http://books.google.com.br/ books?id=uhMpvhwF2d4C\&printsec $=$ frontcover\&client $=$ firefoxa\# $\mathrm{v}=$ snippet\& $\mathrm{q}=$ artesanato $\& \mathrm{f}=$ false $>$. Acesso em: 5 jan. 2015.

TEIXEIRA, Faustino. As Faces do Catolicismo Contemporâneo. In: Revista USP, São Paulo, n.67. Setembro/novembro 2005.

TOMAZ, Laycer. Da Senzala à Capela. Brasília: Editora Universidade de Brasília, 2000.

VIEIRA, S. M. S. Uma análise da trajetória do movimento de Economia Solidária no Brasil após a implantação do primeiro Fórum Social Mundial. RS. Monografia. Curso bacharel em Ciências Econômicas da Universidade Federal de Santa Catarina, 2008. 